\title{
MEMÓRIA E CRÔNICA SOCIAL
}

\section{NA LITERATURA BRASILEIRA CONTEMPORÂNEA}

NONATO, Barbara. Dias vazios. Rio de Janeiro: Nova Fronteira, 2020. 304 p.

Darlan Roberto dos Santos*

Definir a literatura brasileira do século XXI é tarefa difícil. Findada a modernidade, na qual gêneros e movimentos literários eram analisados sob critérios mais precisos, rotulados com (certa) arbitrariedade, nesses "tempos líquidos" (para usar a expressão baumaniana), já não existe o mesmo rigor, quando se trata de organizar, conceitualmente, as mais recentes produções. O fato é que nossa literatura vem se mostrando bastante plural, ramificando-se em vários estilos. Conforme assinala Rebeca Fuks:

\footnotetext{
O rótulo literatura brasileira contemporânea habitualmente se refere às produções literárias lançadas a partir dos anos 2000, embora alguns teóricos apontem datas iniciais diferentes, alguns a partir da década de 80 e 90 . De toda forma, é importante sublinhar que não há entre essas produções literárias nenhum tipo de projeto estético, político ou ideológico comum, não se trata, portanto, de um movimento organizado. (FUKS, 2020, n.p)
}

Entretanto, mesmo com uma imensa gama de temáticas e estratégias discursivas, é possível afirmar que uma das mais evidentes tendências da literatura nacional tem sido a dissecação da memória. Segundo Vivian:

observa-se que o movimento de (des/re)construção da memória é um constituinte fundamental nas narrativas produzidas recentemente no Brasil por um grupo de escritores. A memória tem se revelado selo estruturante das narrativas que tematizam, de diversas formas, a história do país e suas relações com os problemas do presente. (VIVIAN, 2020, p. 82)

\footnotetext{
* Doutor em Literatura Comparada pela Universidade Federal de Minas Gerais (UFMG). Professor da Faculdade Santa Rita. Professor da Faculdade de Direito de Conselheiro Lafaiete.
} 
Nessa seara, muitas vertentes estão sendo exploradas, tais como: a autoficção, o romance histórico e as narrativas urbanas. Dias Vazios, de Barbara Nonato, encaixa-se nesse segmento, que vem obtendo reconhecimento do público e da crítica literária. A obra, que chegou às livrarias no final de 2020, representa, ainda, o que a literatura contemporânea tem de mais novo no campo editorial: a autopublicação.

Escritora de contos e romances desde 2016, Barbara teve, com Dias Vaquios, sua primeira incursão no "grande circuito". Anteriormente, divulgava seus escritos de forma independente - e assim também se deu com esse livro, que teve dois lançamentos. O primeiro deles, em 2019, ocorreu no Kindle Direct Publishing (KDP), plataforma da Amazon, que, desde 2012, oferece a escritores a oportunidade de publicação, livre dos trâmites de uma editora tradicional. Em 2020, a obra conquistou o IV Prêmio Kindle de Literatura, que teve mais de 1800 concorrentes. A vitória garantiu à autora um contrato com a Nova Fronteira - e o "segundo" lançamento; desta vez, no mercado editorial convencional.

A história que essa ficcionista carioca nos traz é a de Rebeca, que, após doze anos em coma, desperta para a nova vida, na qual terá de recompor suas lembranças, compreender o presente e desvendar as implicações do acidente que a deixou desconectada do mundo. Nessa jornada, ela conta com seu grupo de amigos, e transita entre problemas como violência doméstica, relacionamentos abusivos, bullying e corrupção policial. Trata-se, enfim, de um entrecho contemporâneo, em que o tom misterioso mescla-se à crítica social e ao relato urbano. Os enredamentos da memória completam o caleidoscópio, em que rememorações e pensamentos das personagens ajudam a descortinar a trama:

Rebeca voltaria para casa. A partir dali, o futuro seria uma incógnita, assim como o seu passado também era. A vida, ela diria, era uma janela aberta para o ontem, onde o belo, aquilo de que ela se recordava, poderia ser notado quilômetros atrás de si, enquanto à sua frente havia uma vastidão de coisa nenhuma. (NONATO, 2020 , p. 42)

Nessa intermitência entre dimensões temporais, as lucubrações de Rebeca e seus amigos exercem papel determinante, já que, somente a partir delas, será possível situar-se no presente e projetar-se para o futuro. Uma dinâmica que, de alguma forma, é recorrente em outros autores e obras da atual literatura brasileira. Exemplos não faltam: Um defeito de cor (2006), de Ana Maria Gonçalves, em que a memória cumpre o propósito de evidenciar a sociedade escravista do século 19 (que ainda reverbera); a autoficção Antiterapias (2013), de Jacques Fux, na qual o drama familiar se funde às dores do povo judeu, chegando a Com 
armas sonolentas (2018), de Carola Saavedra, anunciado como um "romance de formação" , e que resgata a vida de três mulheres, atingidas pela solidão.

Em comum, essas narrativas (e tantas outras) têm a memória como elemento central, sempre resgatando consciências individuais e coletivas. Algo, talvez, necessário nesses nossos tempos, em que experiências íntimas e acontecimentos de outrora operam como fragmentos, à espera de novos arranjos. Uma vez aflorados, esses estilhaços conduzem a ressignificações no contexto atual e nas mentalidades dos indivíduos pós-modernos. A esse respeito, Seligmann-Silva considera que: "Toda memória é o resultado de conflitos e negociações que se iniciam dentro das pessoas que vivenciaram aquele evento e depois se desdobram nas relações entre os indivíduos, grupos e classes, que se embatem na esfera pública”. (2012, p.64)

Assim, se a obra de Saavedra é declaradamente um "romance de formação", Dias Vazios configura-se como uma história de (re)construção: da vida da protagonista, de suas reminiscências e também de seu grupo social:

Era preciso ressuscitar o grupo, reuni-lo de verdade e apesar de todos os pesares.
Se quisessem seguir em frente e fazer ressurgir o tempo em que comungavam
suas vivências, o passado, ao menos a parte mais tenebrosa dele, deveria, de al-
guma forma, ser despido para que cada um pudesse tirar da bagagem construída
durante aqueles doze anos, uma nova roupagem. Cada um deveria ser o que de
fato era, sem renegar o que se foi, mas privilegiando o que estava por vir. (NO-
NATO, 2020, p. 171-172)

No entremear de passado e presente, a emergência de dores pessoais (de Rebeca e seus companheiros) e questões de ordem comunitária, o que também se revela exitoso, como ressalta Conceição Evaristo, que assina a orelha do livro:

\footnotetext{
A autora é engenhosa em dar voz a múltiplas falas de diversas personagens, revelando vidas entrecruzadas. A escrita que beira um romance policial, o enredo não se limita à descoberta de um culpado, mas traz para a literatura um tema tão necessário como a violência contra a mulher, sem perder a graça nem o tom de ficção. (2020, Orelha do livro)
}

Não por acaso, Conceição é autora de Becos da Memória (2006); outra obra contemporânea sob a égide do testemunho e da crônica social. Assim como a aclamada escritora, Barbara Nonato compõe o grupo de autores que, graças às abordagens realizadas, vêm dando identidade à literatura brasileira que se faz contemporânea, por mobilizar anseios e apreensões dos leitores desta época. De acordo com Costa:

\footnotetext{
${ }^{1} \mathrm{O}$ "romance de formação" (Bildungsroman) é aquele no qual o autor explora, detalhadamente, a trajetória de uma personagem, em seus aspectos físicos, morais, psicológicos e/ou sociais. Geralmente, o enredo desenrolase desde a infância, até a maturidade da persona em questão.
} 
O leitor busca com frequência na literatura as perguntas e possíveis soluções para os acontecimentos, sentimentos e pensamentos que o acometem pelo simples fato de estar vivo. Por isso, a primeira e mais rápida das qualidades que esse leitor atribui a um texto significativo é o poder que a linguagem literária tem de aproximar-se, minimamente, do que acredita ser sua identidade. (COSTA, 2006, p. 8283)

Dias Vazios tangencia identidades esfaceladas; consciências abaladas por problemas tão típicos da urbanidade, marcada pela violência e pela fugacidade dos sentimentos. Embora possa ser lida apenas como uma narrativa de suspense, a obra oferece a oportunidade de escavarmos inquietações que não são apenas das personagens - mas de toda uma geração. Talvez, em função de sua formação de psicóloga, Barbara Nonato tenha arquitetado o romance com um duplo viés, no qual o leitor encontra a ficção, mas também pode enxergar o reflexo de seu caótico e complexo universo. Afinal, nas palavras de Umberto Eco:

\footnotetext{
Ler ficção significa jogar um jogo através do qual damos sentido à infinidade de coisas que aconteceram, estão acontecendo ou vão acontecer no mundo real. Ao lermos uma narrativa, fugimos da ansiedade que nos assalta quando tentamos dizer algo de verdadeiro a respeito do mundo. Essa é a função consoladora da narrativa - a razão pela qual as pessoas contam histórias e têm contado histórias desde o início dos tempos. E sempre foi a função suprema do mito: encontrar uma forma no tumulto da experiência humana. (ECO, 1999, p. 93)
}

Dias Vazios nos possibilita jogar esse jogo, que concilia a fuga da realidade e a tentativa de elucidá-la - por mais paradoxal que possa parecer. É, inegavelmente, um exemplar das "fragmentadas, contraditórias, pluralizadas experiências da nossa contemporaneidade" (PECORARO, 2005, p.20). Um recorte genuíno da literatura atual.

\section{REFERÊNCIAS}

COSTA, Marta Morais da. Mapa do mundo: crônicas sobre leitura. Belo Horizonte: Editora Leitura, 2006.

ECO, Umberto. Seis passeios pelos bosques da fição. São Paulo: Companhia das Letras, 1999.

FUKS, Rebeca. 10 livros para conhecer a literatura contemporânea brasileira. Disponível em: https://www.culturagenial.com/livros-para-conhecer-literatura-contemporanea-brasileira/. Acesso em 17 mar. 2021.

NONATO, Barbara. Dias Vaz̨ios. Rio de Janeiro: Nova Fronteira, 2020.

PECORARO, Rossano. Niilismo e (Pós) Modernidade. São Paulo: Loyola, 2005.

SARAMAGO. As pequenas memórias. São Paulo: Companhia das Letras, 2006.

SELIGMANN-SILVA, Márcio. Narrativas contra o silêncio: cinema e ditadura no Brasil. In: SELIGMANN-SILVA, Márcio et al. (Org.) Escritas da violência. Vol II. Rio de Janeiro: 7Letras, 2012. 
VIVIAN, Ilse. A poética de Carola Saavedra: memória e decolonialidade em Com armas sonolentas. In: LOURENÇO, Camila Morgana; MARKENDORF, Marcio (Org.). A contemporânea literatura brasileira: poéticas do século XXI em debate. Florianópolis: Literatual/UFSC, 2020. p. 81-98.

Recebido em: 18/03/2021.

Aprovado em: 07/07/2021. 